\title{
Neonatology in Beirut, a Country Ravaged by a Financial, Political and Social Crisis
}

Carine Abi Gerges, MD

\section{"While 2020 has been a difficult year \\ for most people, Lebanon has been \\ particularly hit hard by the turn of the \\ decade. In October 2019, thousands took \\ to the streets to demand the overthrow of a corrupt regime."}

While 2020 has been a difficult year for most people, Lebanon has been particularly hit hard by the turn of the decade. In October 2019, thousands took to the streets to demand the overthrow of a corrupt regime. People protested for months while chanting 'Kellon yaane kellon' (All of them means all of them) in reference to the entire ruling class. Political and civil unrest rocked the country against the backdrop of an unprecedented economic and financial crisis: the Lebanese pound plummeted in a free-fall, eventually losing over $80 \%$ of its value with local banks imposing strict restrictions on cash withdrawals preventing depositors from accessing both their savings and salaries. The Coronavirus pandemic made matters substantially worse. The final blow, however, was the Beirut Port explosion on August 4th, 2020. One of the largest non-nuclear blasts ever recorded, it left 150+ dead with 6,000+ injured, 300,000+ homeless, and many more forever scarred by the detonation of almost three kilotons of ammonium nitrate neglectfully stored in the heart of the capital. Three months later, someone has yet to be held accountable.

The health sector, buckling under the pressure, was not spared and is barely holding in this untenable situation. Not long ago, Lebanon was the medical capital of the Middle East. In Beirut alone, over ten hospitals are fully equipped with neonatal intensive care units (NICU), serving as a referral hub for rural areas and serving hundreds of thousands of patients. Among the 70,000 babies born in Lebanon annually, 12\% $(9,000)$ are born prematurely. Additionally, around 9,000 premature births have been recorded among Syrian refugees since 2015, amounting to a total of at least 18,000 documented premature births per year (10). All patients require appropriate financial health coverage to support their medical management, very costly for admitted neonates.

Prior to the financial crisis, less than half of Lebanese citizens

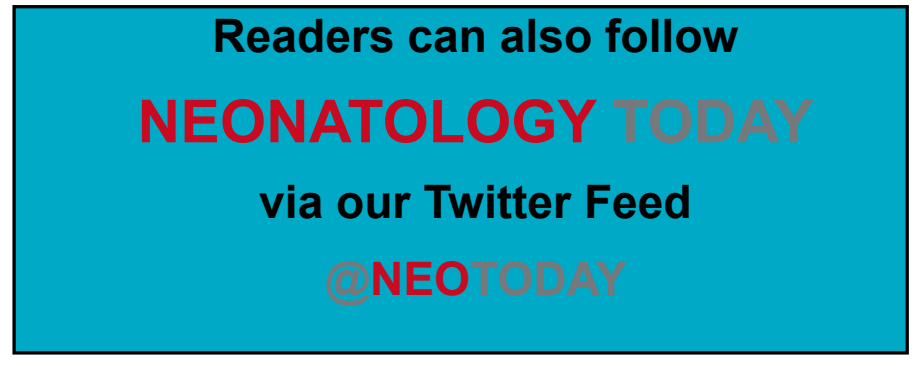

had private or semi-public health insurance plans while the remaining half paid out-of-pocket, partly relying on the Ministry of Public Health (MoPH). As an increasing number of previously insured families lost their jobs and consequently their insurance coverage due to the crisis, many more now resort to an already overwhelmed MoPH to cover their hospital fees. However, some hospitals refuse to admit MoPH-covered patients due to years of accumulated unpaid dues from the government. Soon, only the upper class will be able to afford the estimated $\$ 30,000$ in costs for the care of a premature baby (10).

The cost of NICU hospitalization depends on whether the hospital is public or private, as well as the baby's condition. While most of Beirut's patients are admitted with frequently encountered cases such as prematurity, hyaline membrane disease, necrotizing enterocolitis, and neonatal sepsis, some infants transferred from peripheral hospitals require acute care for rare metabolic and genetic diseases. Although not studied in this specific context, rural areas have a higher prevalence of births with inborn errors of metabolism, likely due to more frequent consanguineous marriage. With the population in these areas being largely workingclass, access to high-quality neonatal intensive care is particularly challenging, the crisis making it even worse. Dany al-Hamod, the director of the NICU at Saint George Hospital University Medical Center (SGHUMC), describes a substantial increase in the number of families unable to afford hospital bills recently, forcing them to run from one non-governmental organization (NGO) to another to gather funds to avoid having to move their child to different facilities, or worse.

The situation is even more dire for refugees. Lebanese is host to the second-largest Syrian refugee population and third largest Palestinian refugee population in the world. This population has increased in the last few years, partly due to the influx of over45,000 'twice-refugee' Palestinians, once settled in Syria, fleeing to Lebanon to escape the civil war (1). Unable to be employed as a result of their refugee status, most do not have access to either public or private health coverage. Instead, they depend

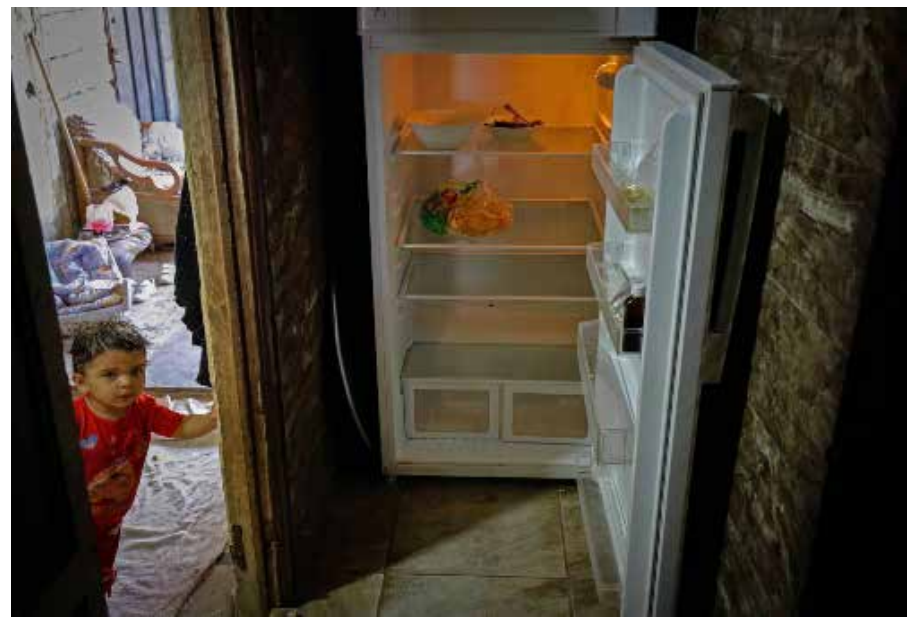

Empty fridges, reflecting the severity of the hyperinflation and the subsequent famine. 


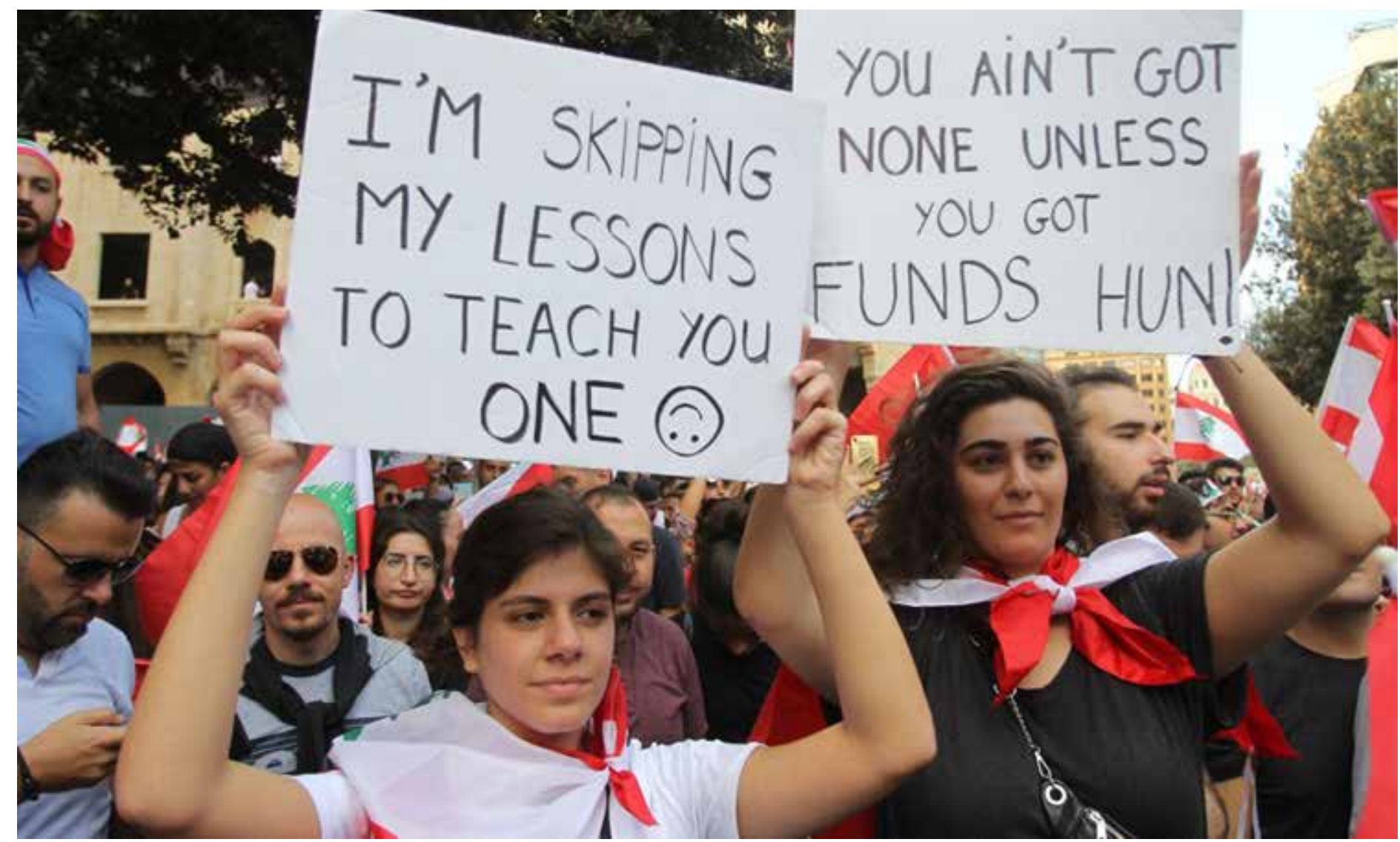

Above, below, and upper photo next page: protests and civil unrest that started over a year ago. Pictures represent young professionals or students taking the streets, AUBMC physicians joining those protests, medical students also joining (and wearing masks prior to 2020!). The last protest picture shows how "female-dominated" these protests were, led by strong women.

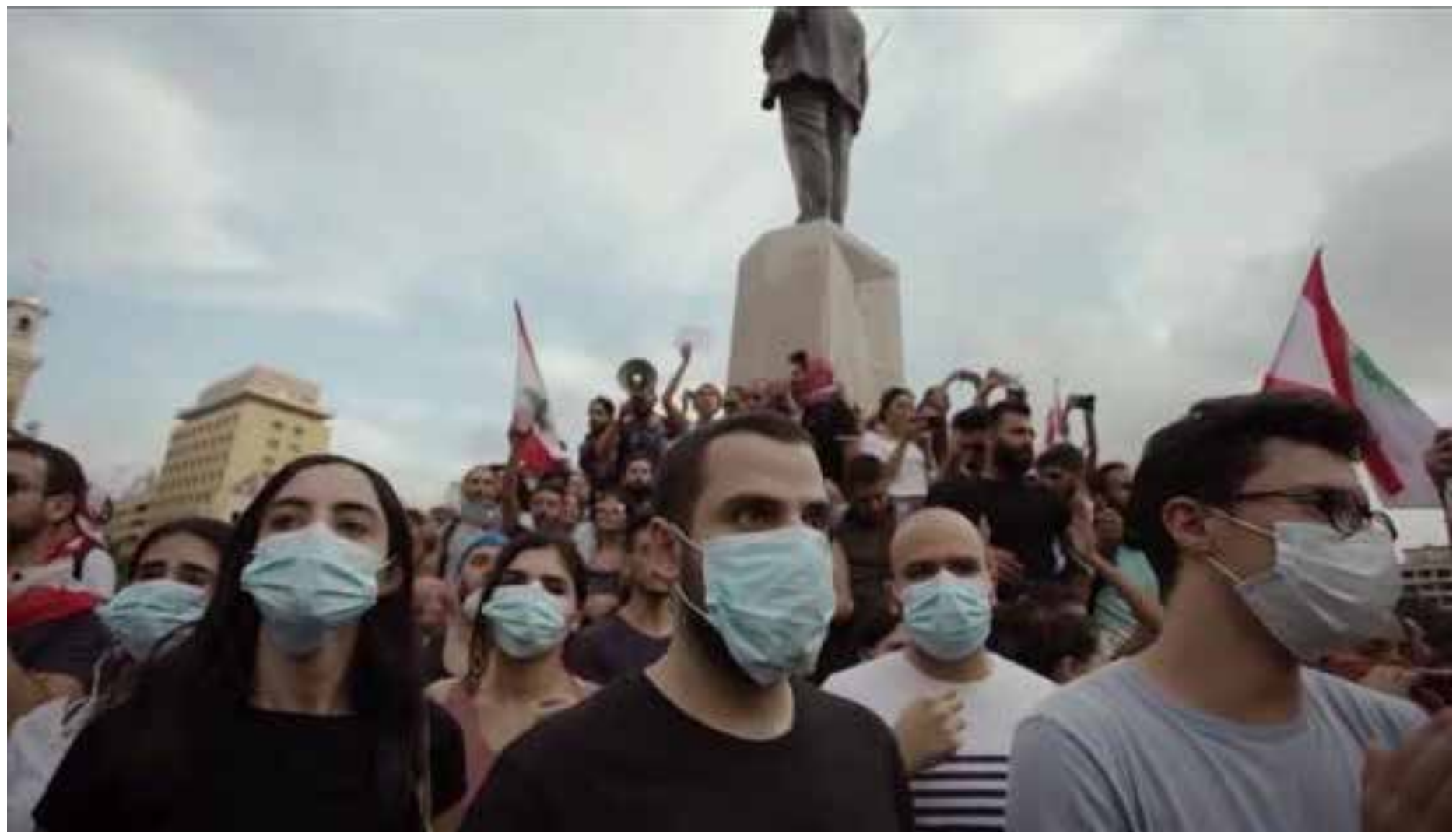




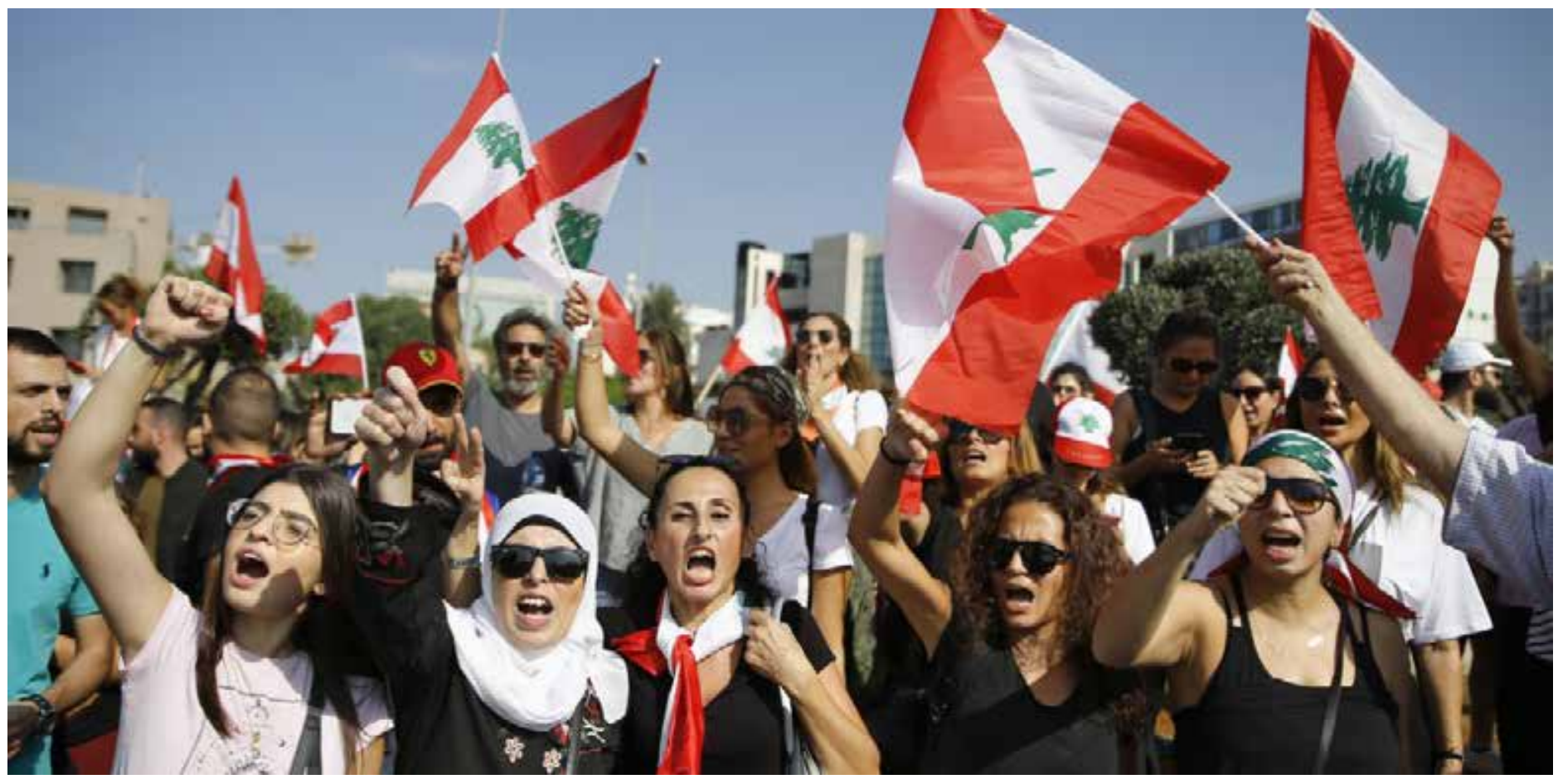

Pictures of a pediatric bed in SGHUMC, showing the extent of the damage done by the explosion

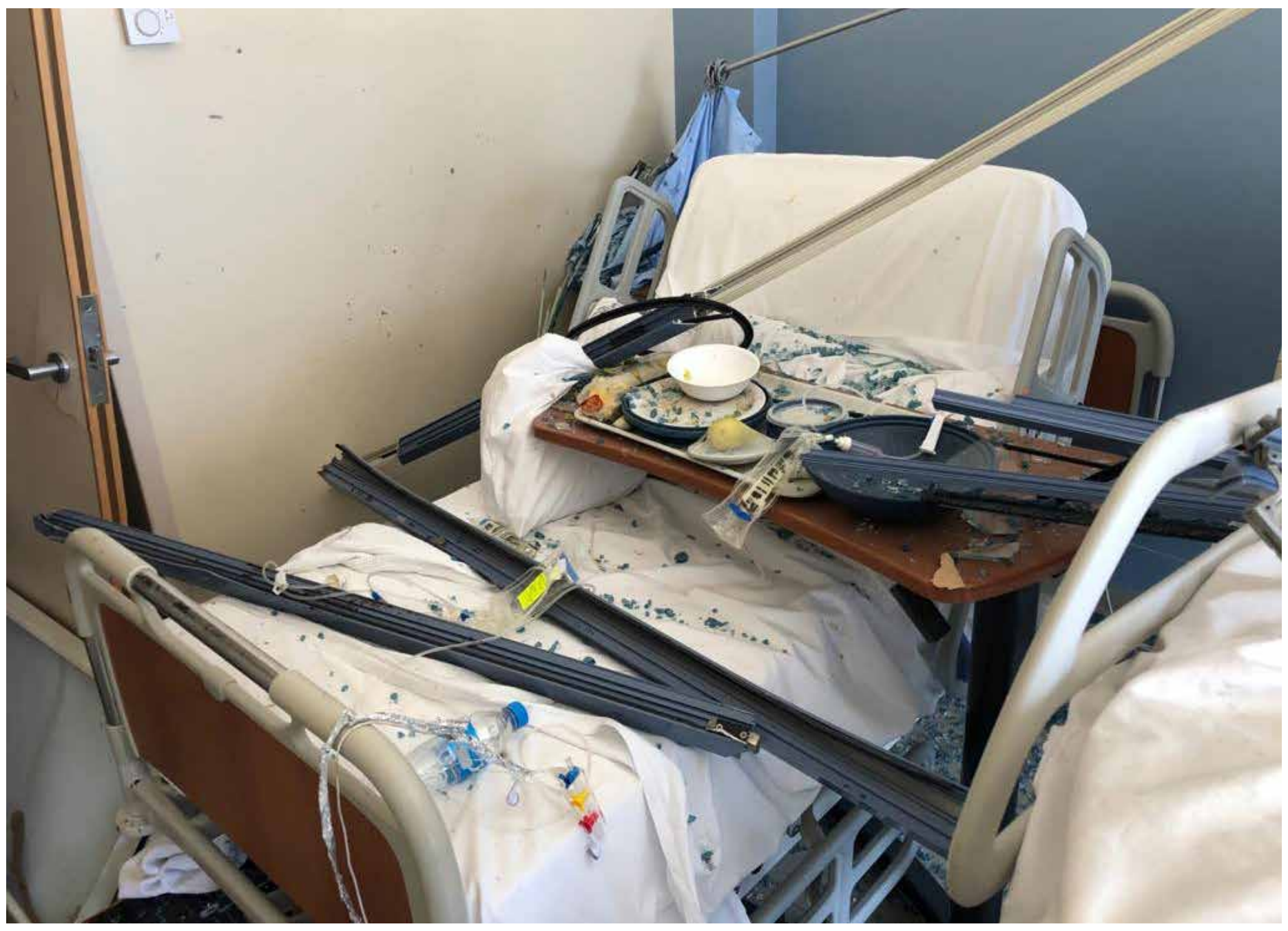




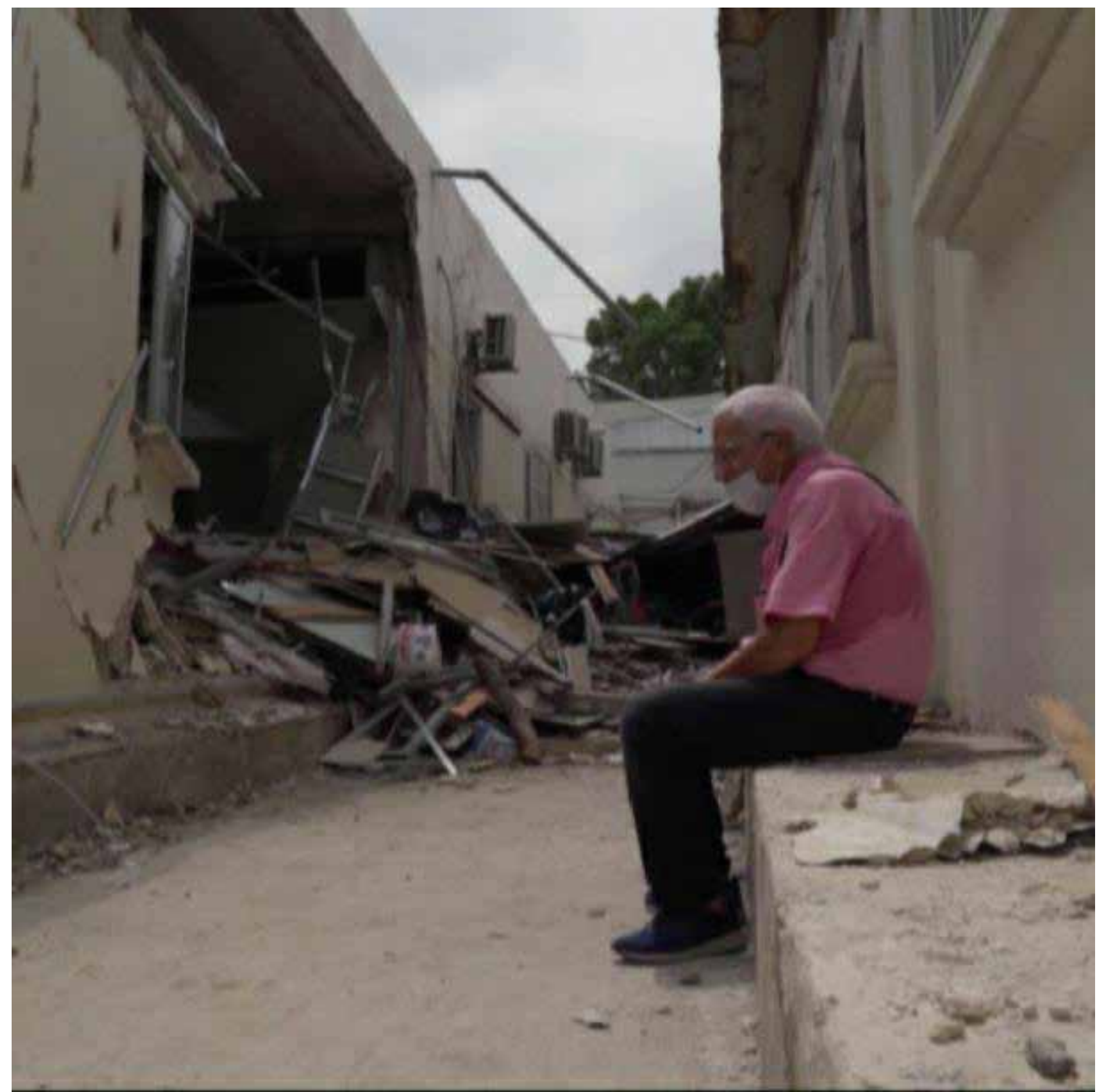

The picture of the man sitting next to the debris is that of Dr. Robert Sacy, next to the Karantina Hospital he built and invested in for the last 4 years only to see it blown away by the blast.

on humanitarian organizations to cover their healthcare needs, namely the United Nations Relief and Works Agency for Palestine Refugees in the Near East (UNRWA) and the United Nations High Commissioners for Refugees (UNHCR). These organizations have been essential to the survival of many newborns in this population, especially that they suffer a higher prevalence of neonatal complications due to inconsistent prenatal care, as well as higher rates of consanguinity (4). These organizations rely entirely on donations and grants, and their ability to cater to their beneficiaries has been severely impacted after the donations they depended on contracted as a result of the ongoing global economic crisis. The severe financial situation that the UNRWA is currently facing threatens millions of refugees and further limits their already minimal healthcare access (9).

The Carlos Slim Center for Children in the Beirut Governmental University Hospital (BGUH - Karantina) was renovated in 2016 by the NGO ASSAMEH - Birth and Beyond through multiple local 


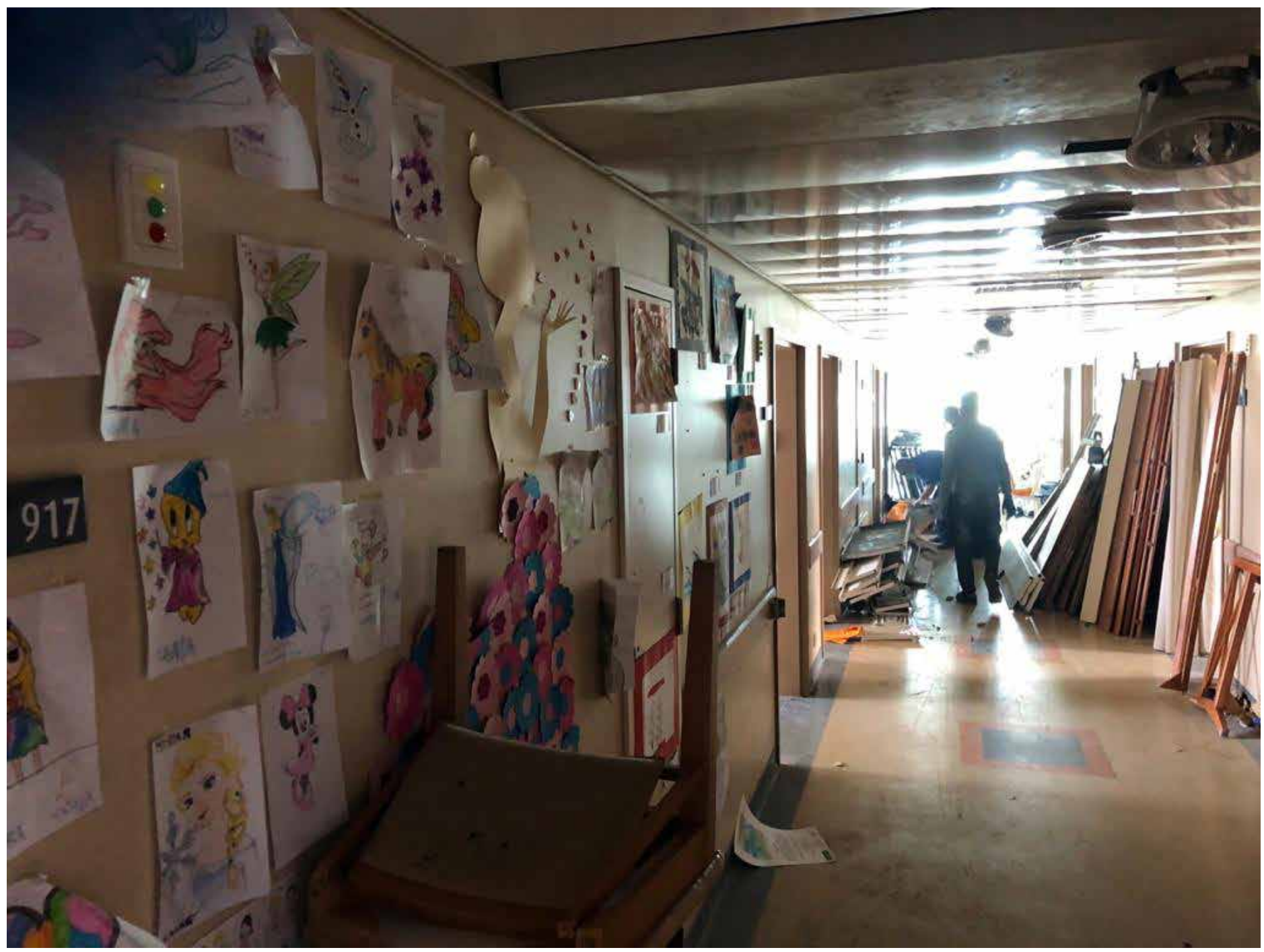

Pictures of a pediatric ward in SGHUMC, showing additional damage done by the explosion

and international donations, building the first fully-equipped public NICU. This center's importance lies in its readiness to "care for those no one cares for." While only $70 \%$ of admitted children are eligible for MoPH-coverage (10), specialized care at this public hospital is provided indiscriminately. Since 2017 , six babies found in trash bins and more than twenty-two "undocumented" children have been taken in and treated by the Karantina team (2). Adding fuel to the fire, this center was heavily damaged by the Beirut Port explosion, nearing total collapse. Inside their incubators, babies sheltered from the debris were evacuated within 3 hours. "An apocalypse - one minute was worse than 20 years of war," says Robert Sacy, head of the Pediatrics Department at the hospital and president of ASSAMEH - Birth and Beyond. What was once a haven for over 1,000 children per year has now been nearly razed to the ground. The remains of paintings of trees, suns, and smiles are now covered with blood on the few walls still standing. What was once joyful is now contaminated with death.

Making matters worse, a surge in the number of cases and ICUs at nearly full capacity, some project that the country might be heading towards an Italy-like scenario if serious long-term precautions measures are not implemented. The daily positivity rate fluctuates between 10 and $20 \%$, and the death toll is $970+$ since February 2020 . The pandemic appears to be mostly affecting adults, with the case-fatality of children under nine years of age at $0.05 \%$ and only one recorded death (7). Although it has been speculated that neonates, due to their immature respiratory physiology and the immune system, might be at a higher risk for COVID-19 related complications, a review of the literature shows no increased risk of severe disease in infected neonates. Conversely, Martin Filho et al. raised concern about how a cytokine storm in pregnant mothers might increase the likelihood of poor neonatal neurodevelopmental outcomes (6). Associate professor of Neonatology at the American University of Beirut Medical Center (AUBMC), Lama Charafeddine, denied that the pandemic had had any noticeable immediate effects on the rate of perinatal complications or congenital malformations or infections. She did contend, however, that it is too early to draw any conclusions regarding this matter. While COVID-19 does not significantly affect the neonatal and pediatric population, Antoine Yazbeck, head of Neonatology at Serhal Hospital, reports a drop in the overall quality of care and staff morale due to increasing physician burnout. Indeed, as of early November, numbers from the doctors' syndicate and the order of nurses (5) show that a total of three doctors had died and seventeen admitted to intensive care units, with 


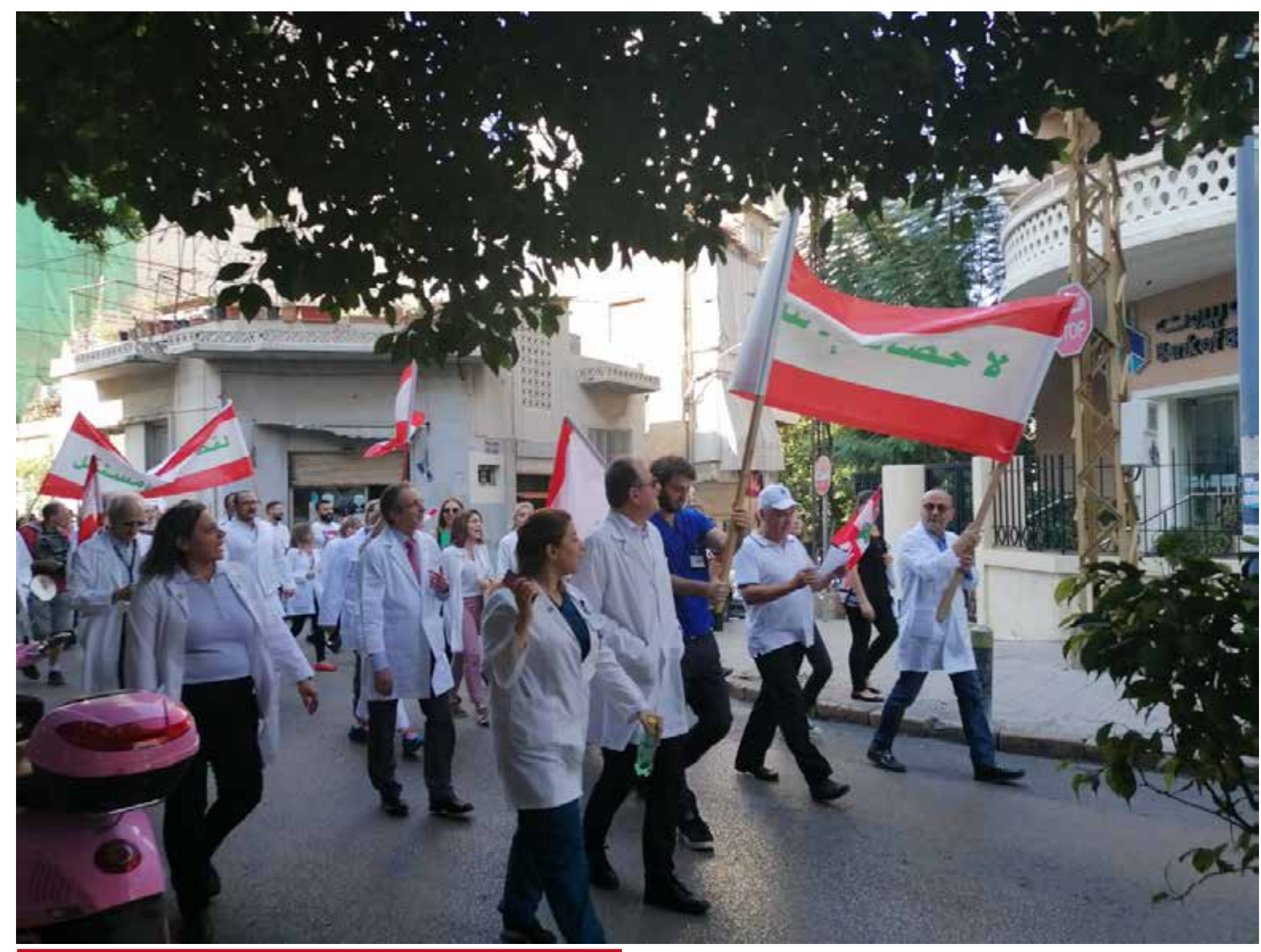

\section{"An apocalypse - one minute was} worse than 20 years of war, 'says

Robert Sacy, head of the Pediatrics

Department at the hospital and president of ASSAMEH - Birth and Beyond. What was once a haven for over 1,000 children per year has now been nearly razed to the ground. The remains of paintings of trees, suns, and smiles are now covered with blood on the few walls still standing. What was once joyful is now contaminated with death."

more than one hundred having been put under home quarantine and over 1,500 nurses having been infected. The pandemic has significantly affected the pediatric healthcare system's overall ca- pacity, draining it in such that neonatal care is becoming severely compromised.

For physicians around the world, and particularly in Lebanon, working conditions have become increasingly difficult. "We see 4-5 kids per day, on a good day", reports Yazbeck, who has reported a ten-fold decrease in daily patient attendance to his clinic. Indeed, the pandemic has led many parents - those who have not migrated yet - to opt-out of vaccination programs and avoid routine follow-ups out of fear of exposure. Additionally, due to currency devaluation, consultation fees, still generally fixed at the same price in Lebanese pounds, are much less profitable to the physician (dropping from the equivalent of \$60/patient to less than \$12/ patient) while still being largely unaffordable for the larger patient population. Maroun Matar, head of the Neonatology Department at Lebanese American University Medical Center (LAUMC), also describes an $80 \%$ decrease in his monthly income despite raising his clinic fees by $10 \%$ whilst food products and basic necessities witness an inflation rate of more than $400 \%$ (3) and half the population is now under the poverty line. Highly qualified and trained physicians, overworked and underpaid, have decided to immigrate for better opportunities abroad. Indeed, over 400 physicians have immigrated in the last couple of months, with more expected to follow suit (8). This has pushed government officials to seek 
international aid to incentivize doctors to stay in the country by offering financial compensation (8). This exodus of physicians and the shortage of medications and medical equipment (hospital suppliers demanding to be paid in hard currency, largely unavailable on the market) has significantly reduced the quality of healthcare in Beirut, once a regional health hub in the Middle East.

\section{"This exodus of physicians and the shortage of medications and medical equipment (hospital suppliers demanding to be paid in hard currency, largely unavailable on the market) has significantly reduced the quality of healthcare in Beirut, once a regional health hub in the Middle East."}

It is crucial to bring to light the difficulties encountered by healthcare workers in developing countries to identify the various factors affecting the quality of care offered to patients. The pandemic has highlighted wide disparities and brought to the fore existing inequalities in developed countries, exposing the need to fill large healthcare delivery gaps to marginalized communities. In a country like Lebanon, shaken by financial precariousness, famine, civil unrest, a large explosion, a mass exodus, and a global pandemic, these disparities have become even more apparent and alarming. This eventful year has highlighted the lack of a national emergency preparedness plan, inadequate infection prevention and control practices, and the absence of an effective healthcare safety net for the uninsured in Lebanon. It is crucial to address these deficiencies for a better-equipped healthcare system in the face of the next blow in order to be able to, at least, give the newborns the gift of time.

\section{References:}

1. Anera. 2020. Helping Refugees In Palestine, Lebanon \& Jordan | Anera. <https://www.anera.org/>

2. Bal du Cedre 2018, 2018. Assameh Birth And Beyond Fundraiser. <https://www.youtube.com/ watch? $v=M m t 5 E 290 / G Q \&$ feature $=e m b$ title $>$

3. Cas.gov.lb. 2020. Central Administration Of Statistics -

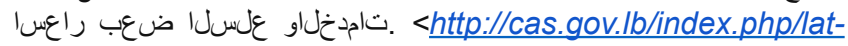
est-news-en/210-2020-02-26-08-10-20>

4. El Sabeh, M., Kassir, M., Ghanem, P., Saifi, O., El Hadi, D., Khalifeh, Y., . . . Kurban, M. (2020). Consanguinity rates among Syrian refugees in Lebanon: A study on genetic awareness. Journal of Biosocial Science, 1-11. doi:10.1017/ S002193202000022X

5. Houssari, N., 2020. Lebanon Heading For Total Lockdown As Health Sector Buckles. Arab News. <https://www.arabnews.com/node/1760751/middle-east>
6. Martins-Filho P.R., Tanajura D.M. COVID-19 during pregnancy: potential risk for neurodevelopmental disorder in neonates. Eur. J. Obstet. Gynecol. Reprod. Biol. 2020 doi: 10.1016/j.ejogrb.2020.05.015

7. Moph.gov.lb. 2020. Moph. <https://www.moph.gov.lb/en/ Pages/2/24870/novel-coronavirus-2019-\#collapse 1>

8. Nakhoul, S. and Abdallah, I., 2020. Hundreds Of Disillusioned Doctors Leave Lebanon, In Blow To Healthcare. U.S. <https://www.reuters.com/article/us-lebanon-crisis-healthcare-insight-idUSKBN27S14W>

9. UNRWA. 2020. Commissioner-General Letter To Staff On The Urgency Of UNRWA's Financial Situation | UNRWA. <https://www.unrwa.org/newsroom/official-statements/commissioner-general-letter-staff-urgency-unrwas-financial-situ$\underline{\text { ation }>}$

10. Sacy, R., 2020. About Us | ASSAMEH - Birth \& Beyond. ASSAMEH - Birth \& Beyond. <https://www.assamehbb.org/ about-us>

NT
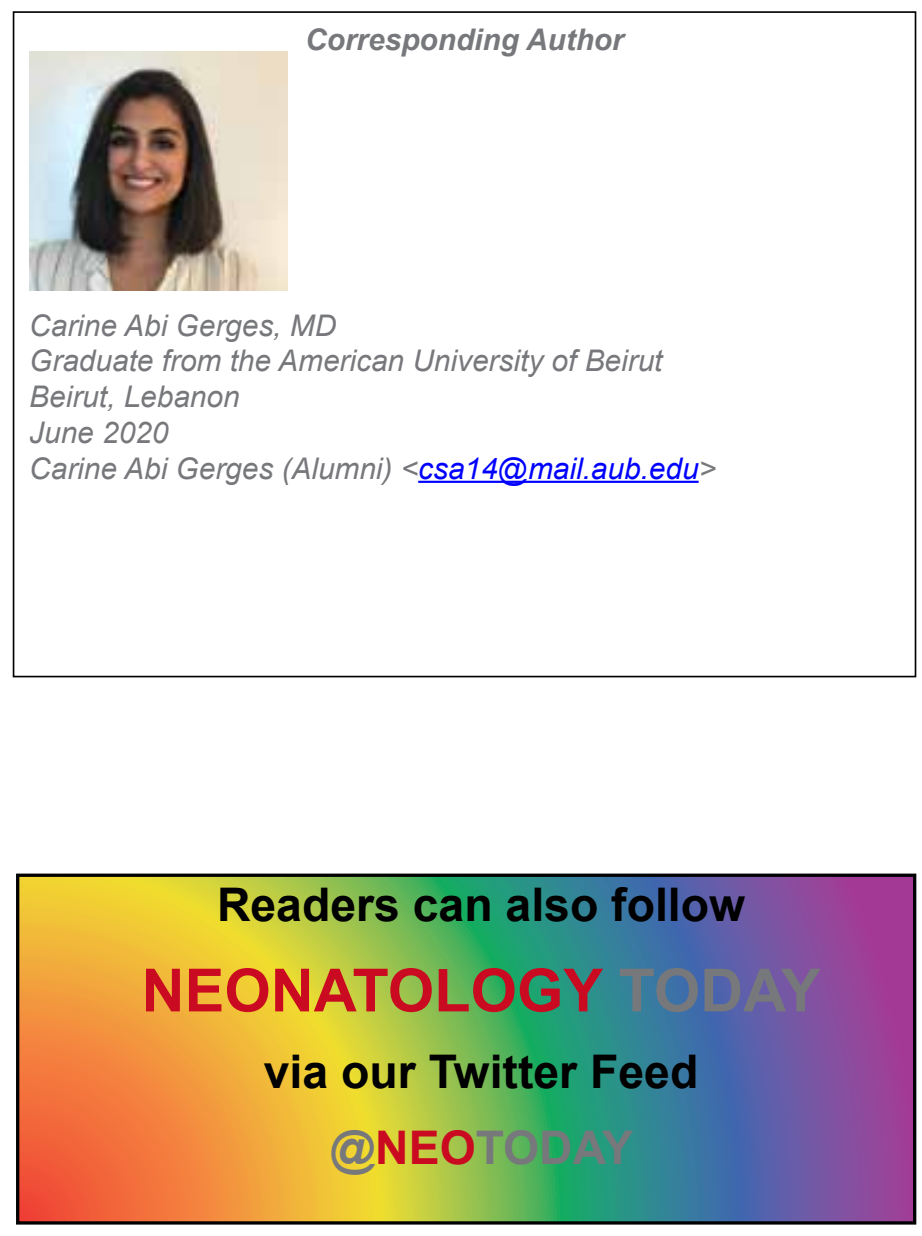

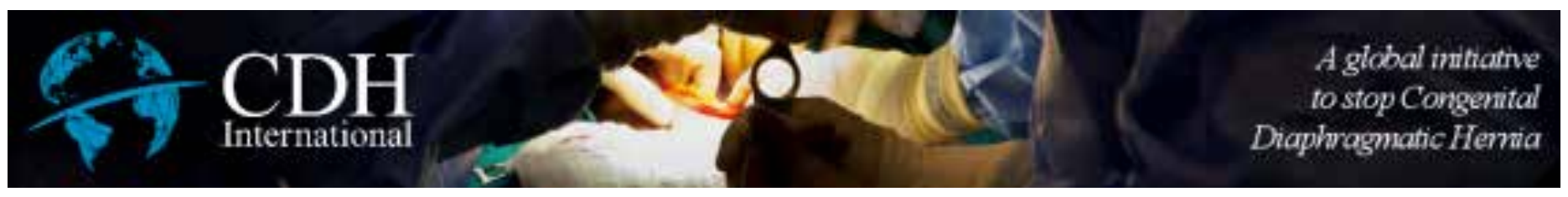

